\title{
PELATIHAN PEMBUATAN JARINGAN LAN DI SMK 1 PGRI PAGAR ALAM
}

\author{
Yogi Isro Mukti ${ }^{1}$, Okta Lesva ${ }^{2}$ \\ ${ }^{123}$ Program Studi Teknik Informatika; Sekolah Tinggi Teknologi Pagaralam (STTP) \\ Jl. M. Siagim No.75 Kel. Karang Dalo, Dempo Tengah, Kota Pagar Alam \\ Telp/Fax: (0730) 621916 \\ e-mail: yogie.isro.mukti@gmail.com ${ }^{1}, \underline{\text { oktalesva@gmail.com² }}$
}

\begin{abstract}
Abstrak
SMK 1 PGRI Kota Pagar Alam sebagai pendidikan kejuruan yang memberikan pelajaran spesifik bila dibanding SMAN/MA, pada SMK 1 PGRI Kota Pagar Alam salah satu peminatannya adalah jaringan komputer, dan sebagai SMKN yang ada di daerah maka sudah barang tentu sulit memenuhi kebutuhan pembelajaran dan praktek terutama pembelajaran core utamanya pada bidang jaringan, sehingga dengan menggandeng civitas akademika STTP yang melakukan pengabdian maka SMK 1 PGRI Kota Pagar Alam melakukan pelatihan pembuatan jaringan LAN, metode yang digunakan adalah seminar dilanjutkan dengan pelatihan praktek. Pada pelatihan untuk mengetahui pemahaman peserta agar pelatihan berjalan lebih efektif dilakukan uji atau tes pendahuluan hasilnya secara teoritis rata-rata semua peserta paham tentang jaringan LAN tetapi ketika diberikan alat atau praktek mereka kebingungan, pada akhir pelatihan dilakukan lagi uji untuk memahami tingkat keberhasilan pelatihan, dan hasilnya peserta pelatihan semuanya semakin baik pemahaman teori dan mampu membuat jaringan LAN dengan menggunakan berbagai topologi yang umum.
\end{abstract}

Kata kunci-Kejuruan, Komputer, Civitas, Pelatihan, Jaringan, Topologi.

\section{PENDAHULUAN.}

Pada Sekolah Tinggi Teknologi Pagaralam (STTP) pengabdian dilakukan setiap semester yang dilakukan oleh seluruh civitas akademika STTP dosen dan mahasiswa, pengabdian dosen dapat dilakukan lebih dari satu kali, sementara pengabdian yang dilakukan mahasiswa yang wajib adalah satu kali selama masa studinya, yang program pelaksanaannya disebut dengan kuliah kerja nyata (KKN), pelaksanaan kegiatan KKN dilakukan tiap tahun secara terjadwal oleh LPPM STTP, dan mahasiswa selain KKN dapat melakukan pengabdian dibawah koordinasi kegiatan UKMUKM yang ada dibawah Badan Eksekutif Mahasiswa (BEM).

Pengabdian oleh dosen dilakukan sesuai dengan kebutuhan dan keahlian yang dimiliki oleh dosen yang melaksanakan pengabdian, seperti pembuatan jaringan LAN ini, dilakukan atas dasar kemampuan dan pengabdian dari pelaksana pengabdian, yang menjiwai dari Tri Dharma Perguruan Tinggi (PT), dan pengabdian ini bagi dosen sangat berguna untuk mengurus jenjang jabatan akademik (JJA) dan pengurusan tunjangan sertifikasi dosen.

SMK 1 PGRI Kota Pagar Alam merupakan sekolah menengah yang membantu pemerintah dalam mencerdaskan masyarakat pagar alam, pada pelaksanaan pendidikan yang dilakukannya untuk konsentrasi jaringan yang ada di SMK 1 PGRI Kota Pagar Alam, dipelajari secara khusus praktek dan teorinya di kelas dan dilaboratorium secara terjadwal, tetapi ternyata pelajaran yang disampaikan didalam kelas dan laboratorium ini dirasa masih ada kekurangan karena keterbatasan waktu dan sarana pada laboratorium sendiri, yang mana modul aplikasi jaringan LAN yang diajarkan harus dipelajari secara berkelompok secara bergantian dan ini menjadi kendala nyata bagi para siswa yang mengantri mempelajari alat dan modul jaringan LAN ini, sehingga 
berdasarkan permasalahan ini pihak SMK 1 PGRI Kota Pagar Alam bersama civitas akademika STTP yang sedang melakukan pengabdian melaksanakan pelatihan pembuatan jaringan LAN bagi Siswa dan Siswi SMK 1 PGRI Kota Pagar Alam.

\section{METODE.}

Pelaksanaan program pengabdian yang dilakukan dosen STTP ini, dilakukan secara mandiri, dan berbarengan kuliah kerja nyata (KKN) mahasiswa sehingga pada pelaksanaanya mahasiswa yang sedang melaksanakan KKN membantu dosen pembimbingnya yang melaksanakan kegiatan pengabdian juga. Dimana metodologi yang digunakan dalam kegiatan Pengabdian kepada masyarakat $(\mathrm{PkM})$ ini dengan cara peserta menyimak (menonton), membaca bersama (modul pelatihan), memahami tools (Software), berinteraksi secara langsung (Aplikatif) dengan software. Sehingga peserta pelatihan benar-benar paham dengan baik.

\subsection{Pengabdian Pada Masyarakat (PkM).}

Program pengabdian kepada masyarakat, merupakan suatu kegiatan untuk membantu masyarakat dalam beraktivitas tanpa mengharapkan imbalan dalam bentuk apapun dari masyarakat. Dimana secara umum program PkM ini dirancang oleh STTP, untuk memberikan kontribusi nyata bagi bangsa dan masyarakat umum, khususnya dalam meningkatkan kesejahteraan dan kemajuan bangsa dan masyarakat. Kegiatan Pengabdian ini merupakan salah satu bagian Tri Dharma Perguruan Tinggi (PT). Bentuk kegiatan Pengabdian Masyarakat ini biasanya: Bakti Sosial dan Mengajar. Tujuan Pengabdian Masyarakat di Perguruan Tinggi, seperti:

1. Melaksanakan alih teknologi informasi, ilmu \& seni pada masyarakat untuk pengembangan martabat manusia dan kelestarian sumber daya alam, yang bisa diobservasi.

2. Meningkatkan daya inovasi teknologi informasi untuk mendorong pembangunan ekonomi Indonesia dengan melakukan komersialisasi hasil dari penelitian yang dilakukan;

3. Mampu memberikan solusi berdasarkan hasil kajian akademik atas kebutuhan, tantangan atau persoalan dihadapi masyarakat, baik langsung maupun tak langsung;

4. Melaksanakan program yang mampu mengentaskan masyarakat tersisih (preferential option for the poor) semua strata, yaitu masyarakat tersisih dari ekonomi, politik, sosial \& budaya;

\subsection{Teknologi Informasi.}

Kata Teknologi Informasi dari kata Information Technology. Sedang kata Technology berdasarkan Kamus yaitu penerapan pengetahuan secara sistematis pada tugas praktis dalam suatu industri. Senada hal ini Sulistyo-Basuki (1992:81) menyatakan Teknologi diartikan pelaksanaan ilmu atau sinonim dengan ilmu terapan. Kata Informasi Oxford Advanced Learners's Dictionary of Current English (1980: 437), sebagai sesuatu yang diberitahukan, pengetahuan dan berita. Sedang kata "Informasi", "pengetahuan", dan "berita" dibedakan. Menurut Teskey (Pendit,1992) data merupakan hasil observasi langsung terhadap suatu kejadian, merupakan perlambangan yang mewakili objek atau konsep di dunia nyata, dilengkapi dengan nilai tertentu.

Informasi merupakan kumpulan data terstruktur, disampaikan seseorang pada orang lain. Sedangkan berita menurut Arifin (1997), didefinisikan informasi menarik, penting dan belum pernah didengar sebelumnya. Kata informasi merupakan sarana baku yang mampu menunjang dan meningkatkan kegiatan bidang Ilmu Pengetahuan, kebudayaan dan teknologi. Pengetahuan, sesuatu yang digunakan manusia untuk memahami dunia, mampu diubah berdasarkan informasi. Pada laporan ini informasi diartikan segala data, fakta dan pengetahuan yang disampaikan pada orang lain melalui berbagai media, dalam bentuk tekstual, gambar, maupun suara.

Sehingga teknologi informasi merupakan istilah baru merupakan terjemahan Information Technology (IT) teknologi informasi merupakan sinonim "Teknologi Baru", karena kaitannya erat dengan mesin microprosesor, seperti mikro-komputer, alat yang bekerja secara otomatis, seperti alat pengolah kata dan lain sebagainya. Pengertian Teknologi Informasi berdasarkan British Advisory Council for Applied Research and Development (Zorkoczy,1990: 12) meliputi bidang ilmu pengetahuan, teknologi dan perekayasaan serta teknik pengelolaan yang digunakan pada penanganan dan pengolahan informasi, penerapan bidang dan teknik tersebut, komputer dan interaksinya dengan manusia dan mesin, masalah sosial ekonomi serta budaya yang berkaitan. 


\subsection{Jaringan LAN.}

Pengertian LAN merupakan suatu jaringan komputer, cakupan wilayah jaringannya sangat kecil atau terbatas. Misalnya, jaringan komputer kantor, sekolah, rumah, atau di dalam satu ruangan saja. Sebuah jaringan yang dibangun pada sebuah lokasi seperti di rumah ataupun gedung perkantoran. Bisa diartikan juga sebagai sebuah sistem komunikasi komputer yang jaraknya dibatasi tak lebih dari beberapa kilometer dan menggunakan koneksi high-speed antara 2 hingga 100 Mbps. LAN memiliki karakteristik yang membedakan dengan jaringan MAN (Metropolitan Area Network) dan WAN (Wide Area Network). Adapun beberapa karakteristik LAN adalah sebagai berikut:

- LAN berada dalam ruang lingkup geografi lebih sempit.

- LAN mempunyai kecepatan perpindahan data yang lebih tinggi.

- LAN berfungsi dengan baik tanpa ada jalur telekomunikasi.

Pada dasarnya fungsi jaringan LAN, untuk menghubungkan beberapa komputer pada jaringan sehingga proses kerja lebih mudah \& cepat. Sesuai dengan pengertian LAN yang dijelaskan sebelumyan, adapun tujuan LAN sebagai berikut:

- Untuk menghubungkan beberapa komputer dalam suatu wilayah kecil.

- Untuk memungkinkan dilakukannya komunikasi antar komputer dan perangkat di jaringan.

- Untuk memungkinkan \& mempercepat proses berbagi data, program komputer di jaringan.

- Membantu menghemat biaya operasional karena perangkat dalam satu jaringan dapat dipakai secara bersama-sama (misalnya: printer, server, dan lain sebagainya).

LAN terdiri dari beberapa komponen yang diatur sedemikian rupa hingga mampu menghubungkan beberapa komputer. Adapun beberapa komponen dasar LAN, sebagai berikut:

- Workstation, yaitu node atau host yang berupa suatu sistem komputer.

- Server, suatu hardware yang fungsinya melayani jaringan dan workstation yang terkoneksi.

- Link, bagian jaringan LAN menghubungkan peralatan seperti workstation \& server fisik.

- Network Interface Card (NIC), dirancang khusus menangani network protocol.

- Network Software, software untuk menjalankan jaringan LAN berfungsi.

\subsection{Pre \& Pos Tes.}

Agar pelaksanaan pengabdian sesuai harapan yang diinginkan oleh pelaksana maka harus dilakukan tes sebelum dan setelah kegiatan pelatihan dilakukan, yang pertama kegiatan Pre tes, suatu kegiatan bentuk pertanyaan yang dilontarkan guru kepada pelajarnya sebelum memulai suatu pelajaran yang baru. Pertanyaan yang ditanya, materi akan diajar pada hari itu (materi baru). Pertanyaan biasanya dilakukan guru di awal pembukaan pelajaran. Pre tes diberikan maksudnya untuk mengetahui apakah ada diantara pelajar sudah mengetahui mengenai materi akan diajarkan. Pre tes juga diartikan sebagai kegiatan menguji tingkatan pengetahuan pelajar terhadap materi akan disampaikan, kegiatan pre tes dilakukan sebelum kegiatan pengajaran diberikan. Adapun manfaat dari diadakannya pre tes, untuk mengetahui kemampuan awal pelajar mengenai pelajaran yang disampaikan. Dengan mengetahui kemampuan awal pelajar ini, guru dapat menentukan cara penyampaian pelajaran akan di tempuh.

Sementara tes yang terakhir yaitu pos tes. Pos tes merupakan bentuk pertanyaan yang diberikan setelah pelajaran/materi telah disampaikan. Singkatnya, pos tes adalah evalausi akhir saat materi yang di ajarkan pada hari itu telah diberikan yang mana seorang guru memberikan pos tes dengan maksud apakah murid sudah mengerti dan memahami mengenai materi yang baru saja diberikan pada hari itu. Manfaat dari diadakannya post test ini adalah untuk memperoleh gambaran tentang kemampuan yang dicapai setelah berakhirnya penyampaian pelajaran. Hasil post test ini dibandingkan dengan hasil pree test yang telah dilakukan sehingga akan diketahui seberapa jauh efek atau pengaruh dari pengajaran yang telah dilakukan, disamping sekaligus dapat diketahui bagian bagian mana dari bahan pengajaran yang masih belum dipahami oleh sebagian besar siswa.

\subsection{Penyelesaian Masalah.}

SMK 1 PGRI Kota Pagar Alam, sistem pembelajaran sudah cukup baik secara terstruktur dan terjadwal dengan baik tiap mata pelajaran, teori atau pun pelajaran yang praktek. Tetapi walau pun sedemikian baik sistem yang terstruktur tetapi memiliki keterbatasan dari sisi waktu atau pelaksanaan pembelajaran dalam kelas, selain itu sarana terdapat beberapa modul yang kekurangan 
alat karena jumlah mahasiswa yang banyak, sehingga keterbatasan ini memberikan kesempatan kepada civitas STTP untuk dijadikan program pengabdian, maka pada kesempatan ini dilakukan pengabdian pelatihan jaringan LAN, untuk menyelesaikan permasalahan kekurangan pemahaman siswa kepada jaringan LAN karena kekurangan waktu belajar dilakukanlah pengabdian oleh Civitas STTP.

\section{PEMBAHASAN DAN HASIL.}

\subsection{Realisasi \& Pemecahan Masalah.}

Realisasi dan pemecahan permasalahan yang dihadapi SMK 1 PGRI Kota Pagar Alam dalam lebih memahamkan materi pelajaran bagi para siswa dan siswinya, maka pada pelatihan kali ini permasalahan yang dilakukan penyelesaiannya adalah memahamkan siswa siswi SMK 1 PGRI Kota Pagar Alam dalam pembuatan jaringan LAN praktek dan teori. Pada pelaksanaannya pengabdian didahului dengan Pre tes, pre tes dilakukan pada awal pelatihan dimana seluruh peserta diberikan kuisioner untuk mengetahui tingkat pemahaman peserta terhadap terhadap materi jaringan LAN yang akan disampaikan, maka jika dideskripsikan dalam tabel maka berikut merupakan rincian kegiatan yang dilaksanakan:

Tabel 1. Kegiatan

\begin{tabular}{|c|c|c|}
\hline Waktu & Materi & Penyaji \\
\hline $\begin{array}{l}08.00-09.00 \\
09.00-09.30\end{array}$ & $\begin{array}{l}\text { Pre Test } \\
\text { Pengantar teknologi jaringan dan internet }\end{array}$ & \multirow[b]{2}{*}{$\begin{array}{l}\text { Yogi Isro Mukti } \\
\text { dan } \\
\text { Okta Lesva }\end{array}$} \\
\hline $\begin{array}{l}12.00-12.30 \\
12.30-13.00\end{array}$ & $\begin{array}{l}\text { Pengenalan topologi jaringan dan tata cara melakukan } \\
\text { pembuatan jaringan } \\
\text { Praktek melakukan pembuatan jaringan LAN } \\
\text { Post-test }\end{array}$ & \\
\hline
\end{tabular}

Setelah pre tes selanjutnya dilakukan materi pendahuluan yaitu pengantar teknologi jaringan dan pengenalan dasar-dasar internet, agar para peserta pelatihan memahami lebih baik tentang perkembangan teknologi informasi dalam hal ini tentang internet yang sangat penting dalam segala hal, karena segala hal saat ini menggunakan aplikasi internet.

Berikutnya, dikenalkan tentang topologi, tools yang diperlukan pada pembuatan jaringan dan cara-cara membuat jaringan LAN untuk diaplikasikan untuk berbagai keperluan. Terlebih dahulu diperkenalkan peralatan pembuatan jaringan LAN. Selanjutnya peserta pelatihan mengenal topologi, peralatan dan lain-lain selanjutnya para peserta pelatihan dipersilahkan mencoba membuat jaringan sendiri mulai dari belajar menyambungkan kabel menggunakan tank krifting, disambungkan dengan beberapa komputer, melakukan setting dan sebagainya. Peserta diminta mempraktekan seluruh materi yang diberikan.

Terakhir, dilakukan pos tes untuk mengetahui tingkat pemahaman para peserta terhadap materi yang telah disampaikan dan mengetahui apakah para siswa SMK 1 PGRI Kota Pagar Alam telah memahami seluruh materi dan mampu melakukan instalasi atau pembuatan jaringan LAN yang diinginkan SMK 1 PGRI Kota Pagar Alam, sehingga menjadi Softskills tambahan bagi para peserta yang mengikuti pelatihan.

\subsection{Pembahasan \& Hasil.}

Berikut ini merupakan pembahasan dan hasil dari pelatihan yang sudah dilaksanakan pada SMK 1 PGRI Kota Pagar Alam, yang mana kegiatannya telah dijelaskan pada 3.1, berdasarkan urutan tersebut diatas maka berikut hasilnya. Pertama, hasil dari pre tes yang dilakukan peserta telah memahami dengan baik teori dan cukup paham terhadap perangkat atau tools untuk membangun jaringan LAN, tetapi dalam hal ini pemahamannya masih harus lebih banyak dalam melakukan praktek secara langsung, sehingga pada pelatihan ini lebih banyak praktek membuat jaringan LAN.

Kedua, pengenalan teknologi jaringan dan internet, hasilnya seluruh peserta memahami teori menjadi sangat baik. Ketiga, pengenalan topologi dan tata cara membuat jaringan LAN, peserta memahami dengan baik seluruh topologi jaringan dan paling utama jaringan LAN dan 
mengaplikasikannya kedalam jaringan secara nyata. Keempat, peserta hasilnya seluruhnya (100\%) mampu melakukan instalasi jaringan LAN secara baik hal ini dibuktikan dengan dari hasil pos tes yang dilakukan, setelah pelatihan. Terakhir, dilakukan tes lagi, yaitu pos tes dan hasilnya membuktikan dari praktek bagian keempat seluruh peserta mampu dengan baik melakukan instalasi jaringan LAN.

Tabel 2. Keberhasilan Pelaksanaan Kegiatan

\begin{tabular}{|l|l|}
\hline \multicolumn{1}{|c|}{ Materi } & \multicolumn{1}{|c|}{ Hasil } \\
\hline Pendahuluan & $\begin{array}{l}\text { Narasumber mampu memberikan materi yang paling sesuai } \\
\text { dengan kebutuhan dari para peserta pelatihan. }\end{array}$ \\
\hline Pengantar jaringan \& Internet & $\begin{array}{l}\text { Peserta lebih paham dengan teknologi jaringan dan internet } \\
\text { yang dihubungkan dengan berbagai aplikasi jaringan. }\end{array}$ \\
\hline $\begin{array}{l}\text { Topologi jaringan \& cara } \\
\text { membangun jaringan LAN }\end{array}$ & $\begin{array}{l}\text { Pemahaman perserta semakin baik dan mengenal dengan } \\
\text { topologi yang diaplikasikan pada jaringan, dan mampu } \\
\text { memahami tata cara membangun jaringan LAN yang sesuai } \\
\text { dengan kebutuhannya. }\end{array}$ \\
\hline Praktek jaringan LAN & $\begin{array}{l}\text { Hasilnya peserta mampu membangun jaringan LAN dengan } \\
\text { baik, dan sesuai dengan keperluannya. }\end{array}$ \\
\hline Penutup & $\begin{array}{l}\text { Hasilnya peserta sangat memahami jaringan LAN dan mampu } \\
\text { membangun jaringan LAN. }\end{array}$ \\
\hline
\end{tabular}

Melalui uraian diatas dapat di pahami hasil dari kegiatan pengabdian kepada masyarakat (PkM) yang dilakukan ini softskills para peserta siswa dan siswi yang mengikuti pelatihan jaringan LAN meningkat dengan sangat baik dan pelatihan berhasil dengan sangat baik sekali, sehingga peserta pelatihan menjadi lebih optimis dalam menghadapi masa depannya ini memberikan keuntungan bagi SMK 1 Kota Pagar Alam karena masyarakat semakin percaya dan bagi STTP dengan pengabdian dan pelatihan ini mendapat calon atau peminat baru untuk kuliah di STTP dan lebih meningkatkan kepercayaan pada kemampuan alumni yang sangat baik, sehingga bisa diidentifikasi berikut merupakan hasil akhirnya, yaitu:

a. Para peserta pelatihan Jaringan LAN siswa dan siswi SMK 1 PGRI Kota Pagar Alam mempunyai pengetahuan \& pemahaman baik tentang Jaringan LAN.

b. Seluruh siswa dan siswi SMK 1 PGRI Kota Pagar Alam yang menjadi peserta sangat paham terhadap teknologi informasi yang lebih aplikatif.

c. Para guru SMK 1 PGRI Kota Pagar Alam sudah terbantu dalam pemberian pemahaman terhadap teknologi informasi up to date yang aplikatif, terutama jaringan LAN.

d. Para siswa \& siswi peserta pelatihan pembuatan jaringan LAN lebih memahami lagi tentang aplikasi pembelajaran TIK yang disampaikan oleh guru didalam kelas, jauh lebih memahami secara lebih aplikatif pada LAN.

e. Seluruh peserta siswa siswi SMK 1 PGRI Kota Pagar Alam menjadi lebih merasa percaya diri saat terjun pada dunia kerja dan lebih memiliki pemahaman terhadap teknologi jaringan LAN.

\section{KESIMPULAN}

Pengabdian kepada masyarakat ini yang dilaksanakan di SMK 1 PGRI Kota Pagar Alam dengan tujuan melatih siswa dan siswi dalam melakukan pembuatan jaringan LAN didapatkan kesimpulan sebagai berikut:

a. Proses pembelajaran secara langsung ternyata telah mampu meningkatkan semangat siswa belajar menjadi lebih baik (giat), mempelajari teknologi jaringan LAN.

b. Menambah softskills siswa-siswi SMK 1 PGRI Kota Pagar Alam, semakin paham dan ahli dengan jaringan LAN.

c. Meningkatkan percaya diri siswa \& siswi peserta pelatihan jaringan dengan kemampuannya ketika terjun di masyarakat. 
d. Membantu guru pelajaran jaringan pada SMK 1 PGRI Kota Pagar Alam dalam hal memahamkan siswa terhadap suatu aplikasi tertentu dari jaringan LAN.

\section{SARAN}

Berdasarkan pengalaman pada pelaksanaan pengabdian, dan dilihat serta dirasakan pengabdi saat melakukan pengabdian $(\mathrm{PkM})$ ini, maka penulis dalam hal ini bisa memberikan saran:
a. Waktu pelatihan harus diperpanjang agar peltihan lebih sesuai dengan harapan.
b. Tempat pengabdian di perbanyak sehingga pengabdi dapat memilih.
c. Lebih transparan dalam pembiayaan.

\section{UCAPAN TERIMA KASIH}

Terima kasih semua peserta.

\section{DAFTAR PUSTAKA}

[1] Indonesia Services Education HP Tim, 2001, Manajemen Sistem Belajar Di Dunia Maya, Majalah Info Komputer.

[2] M.H Jogiyanto, 1995, Pengenalan Komputer, Andi Offset Yogyakarta.

[3] Muslim, B. 2018. Pelatihan aplikasi editing video dengan filmora., Laporan Pengabdian Kepada Masyarakat, LPPM STT Pagaralam.

[4] Muslim, B. 2018. Pelatihan Pembuatan Blog Bagi Guru Ma Ponpes Darul Mutaqin Kota Pagaralam. NGABDIMAS. Vol 1. No.1. Bulan Juni, Hal. 6-11

[5] B. Muslim, Pengantar teknologi informasi. Yogyakarta: Deepublish, 2017.

[6] Muslim, B. (2018). Analisis system informasi (SI) terintegrasi di Perguruan Tinggi (PT) (Studi Kasus: STT Pagaralam). Jurnal Teknologi Informasi MURA, Vol 10. Page 83-91.

[7] Menristekdikti. 2016. Panduan Pelaksanaan Penelitian dan Pengabdian Masyarakat di Perguruan Tinggi Edisi X Tahun 2016. hlm. 4.

[8] Muslim, B (2014). Analisis rencana aplikasi teknologi informasi pada STT Pagar Alam. Proseding semnastik dan Magma. Issue: Aplikasi Teknologi dan sistem Informasi. PPP UBD Pres. Pages 397-404.

[9] Hutchinson E. Sarah and Sawyer C. Stacey, 2000, Computers, Communications \& Information, McGraw Hill Companies Inc.

[10] Horsley, M., Knight, B., \& Huntly, H. 2010. The role of textbooks and other teaching and learning resources in higher education in Australia: Change and continuity in supporting learning. IARTEM 1-Journal. 3(2). 43-61.

[11] Sadiman, A.S., Rahardjo, R., Haryono, A., \& Rahardjito. 2006. Media pendidikan: Pengertian, pengembangan, dan pemanfaatan. Jakarta: Rajagrafindo Persada. 